\title{
Aging in Rural Appalachia: Perspectives from Geriatric Social Service Professionals
}

\author{
Natalie D. Pope \\ Diane N. Loeffler \\ D. Lee Ferrell
}

\begin{abstract}
This paper uses qualitative methodology to explore the experience of growing old in rural Appalachia. Given the growing population of older adults seeking and utilizing services, it is important to understand the challenges and specific needs related to aging. Within the context of rural Appalachia, these challenges and needs may be different than those in urban areas or areas outside of the region itself. From interviews with 14 geriatric service providers in rural southeast Ohio, the authors were able to identity three prevalent themes associated with aging in rural North Central Appalachia: scarcity of resources, valuing neighbors and family, and the prevalence of drug use. These findings suggest that preparation and ongoing training of rural geriatric social workers should include attention to topics such as substance abuse and strengthening social support networks that often exist in these regions.
\end{abstract}

Keywords: Rural aging, older adults, Appalachia, qualitative

The 65 and over population is growing exponentially, in large part because of aging baby boomers. From 2007 to 2030, the number of older adults will have increased by $89 \%$, with the population as a whole increasing $21 \%$ (Houser, Fox-Grage, \& Gibson, 2009). Between 1950 and 2000, life expectancy increased by eight years for men and women alike (Kinsella \& Velkoff, 2001). In Appalachia, $15.2 \%$ of the population is 65 or older, compared with $13.2 \%$ of the overall U.S. population. Moreover, two-thirds of elders in the Appalachian region reside outside metropolitan areas. In Appalachian Ohio, where the present study takes place, $15.7 \%$ of the population is 65 or older (Pollard \& Jacobson, 2014). Thus, while the aging population is growing at the same rate in Appalachia and the rest of the country, Appalachia has a higher concentration of older adults (Haaga, 2004; Pollard \& Jacobson, 2014).

In a systematic literature review on attention to rural topics in social work journals, Slovak, Sparks, and Hall (2011) found a low proportion of research-focused articles on rural populations. Out of more than 3,000 peer-reviewed articles published between 2004 and 2008 in 14 top social work journals, only 71 articles had a distinctly rural focus. We support these authors' conclusions that, "Empirical studies about the issues and needs of rural populations and evaluations of interventions are needed to address gaps in services, improve programs, and assist in policy matters" (p. 435). In light of the scarcity of social work research on rural topics, this study focuses on a particular subgroup of rural America - older adults. This paper aims to provide an in-depth description of rural aging,

Natalie D. Pope, Ph.D., LCSW, is an Assistant Professor; Diane N. Loeffler, Ph.D., MSW, is a Senior Lecturer; and D. Lee Ferrell, MSW, is a PhD student; all in the College of Social Work at the University of Kentucky in Lexington, KY. The authors would like to express their appreciation for support from the Ohio University College of Health Sciences and Professions.

Copyright (C) 2014 Advances in Social Work Vol. 15 No. 2 (Fall 2014), 522-537 
as viewed through the experiences of rural social service providers in a rural region of North Central Appalachia.

The Appalachian Region of the U.S. is, for the purpose of research and inquiry, divided into sub-regions. In 2009, the Appalachian Regional Commission (ARC) refined the subregion classification, moving from a three sub-region classification (North, Central, Southern) to a five sub-region classification that includes North Central and South Central regions. These revised classifications reflect "contiguous regions of relatively homogenous characteristics (topography, demographics, and economics)" (ARC, 2009, para. 2). Thus, for this paper, statistics and discussion of the North Central Appalachian region are provided when available. The Housing Assistance Council (Housing Assistance Council [HAC], 2012), however, prefers to look at Central Appalachia as a whole. Thus, reference to Central and North Central Appalachia are overlapping at times and both used in this paper.

\section{Review of the Literature}

There is much evidence documenting the poor physical health of Appalachians (Halverson, Barnett, \& Casper, 2002; Halverson, Ma, \& Harner, 2004; Smith \& Holloman, 2011), and of older Appalachians in particular (Behringer \& Friedell, 2006; Haaga, 2004). The region has a greater percentage of older adults with disability and chronic conditions (Halverson et al., 2004). Compared to a disability rate of $36.8 \%$ among those 65 and older across the U.S., four out of ten elders living in Appalachia are disabled. In Appalachian Ohio, rates of disability among older adults are higher than the state average $(38.2 \%$ compared to 35.8\%) (Pollard \& Jacobson, 2014). Cancer rates are also high in Appalachia and the availability of treatment options (both preventive and therapeutic) are limited (Baldwin et al., 2008; Deskins et al., 2006; Lengerich et al., 2005). Chronic diseases such as diabetes are also prevalent in the region. Diabetes rates are high for both older adults and the general population (Barker, Gerzoff, Crespo, \& Shrewsberry, 2011; Della, 2011). In general, rural communities are notoriously underserved with respect to health care providers and services (Kropf, 2004) and alternative long-term care services are also scarce in these communities (Buckwalter \& Davis, 2011). As a result, many often rely upon themselves, friends, and family members for a more informal level of care (Blieszner, Roberto, \& Singh, 2002; Hayes, 2006).

In addition to poor physical health, the region faces other challenges that likely affect those growing old in the region. High poverty rates plague the area. Taken as a whole, the region's poverty rate is $16.6 \%$; in the North Central sub-region, the poverty rate is $17.3 \%$ (Pollard \& Jacobson, 2014). In North Central Appalachia, 9.7\% of older adults are living in poverty, as compared to a $9.4 \%$ poverty rate for older adults across the U.S. (Pollard \& Jacobson). In Appalachian Ohio, older adults are slightly less likely to be poor than older adults throughout the region (9.0\% live in poverty) yet are more likely to be poor than older adults in the state of Ohio as a whole (7.8\% live in poverty) (Pollard \& Jacobson). Given high poverty rates, it is not surprisingly that many young people are moving out of the small towns and communities in search of work and opportunity (Haaga, 2004). This contributes to a lack of available and qualified adults to work in long-term care and other health-related jobs within the region. 
The social and cultural milieu of the region may also affect health perceptions, experience of illness, and preventative and curative behaviors (Furnham, 1994). Older Appalachians have a unique culture that likely affects their experiences with aging and long-term care. The "deep sense of place" relationship that Appalachians often have to their communities (Coyne, Demian-Popescu, \& Friend, 2006), coupled with a more widespread desire to age in place might be detrimental to older adults accessing adequate medical care (AARP, 2000; Alley, Liebig, Pynoos, Banerjee, \& Choi, 2007). The Appalachian characteristic of living in the "here and now" may prove harmful if it prevents forethought and keeps adults from making concrete plans for later life (Hayes, 2006). Rather than preparing for potential care needs, some middle age and older adults rely on reciprocity from family and friends. Relying on close relationships for informal care enforces a tendency not to ask for help (particularly in the means of formal care) and the expectation of others to offer help; this can be particularly detrimental in receiving timely and appropriate care (Hayes, 2006; Pope, 2013).

Growing old in rural areas may provide different challenges to elders and their families than aging in large metropolitan communities. Thus, this study sought to better understand the challenges and specific needs related to aging in rural Appalachia. By asking service providers to share their experiences and stories, we are better able to think about how to develop interventions and services that will support effective service delivery systems in our small towns and communities. Given that Appalachia is distinct in terms of its geography, history, culture, and current social problems, it is important to consider the experiences of rural Appalachian professionals apart from that of rural professionals in other regions. The region has distinct cultural traditions (Lengerich et al., 2006) and although some may put Appalachians at risk for health and social consequences in late life (e.g., independence and fatalism), other values and beliefs may be protective (e.g., strong family ties and religiosity) (Coyne et al., 2006; Hartley, 2004).

\section{Methodology}

This study utilized qualitative methodology to allow for the voices of the study participants to be heard and for themes to emerge from their experiences. Because little is known about rural aging - and specifically from rural social service providers who engage with and serve rural elders - this grounded approach was preferable. A distinguishing feature of qualitative inquiry is that it "elevates context as critical to understanding [a phenomenon]" (Patton, 2002, p. 63). North Central Appalachia, specifically rural southeast Ohio, serves as the study setting and its context is vital to this research.

\section{Sample Selection and Recruitment}

Nonrandom, purposive sampling was used to locate participants who: 1) self-identified as a direct service provider; 2) provided services to older adults currently or within the past year; 3) provided services to elders living in rural Appalachia; 4) possessed at least one year's experience with older adults in order to be able to reflect on their experiences; and 5) lived and worked in southeast Ohio (as defined by the Ohio Environmental Protection Agency, n.d.). The first author utilized professional and personal contacts to reach out to 
potential participants who met the inclusion criteria. Initial contact was made through either an email or phone inquiry about the professional's potential interest in the project.

Fourteen geriatric social service providers, ranging in age from 24 to 69, comprised the final sample (see Table 1). One social service professional who met the criteria for inclusion chose not to participate due to time constraints. Participants averaged 13 years of practice experience and 11 had more than 5 years of experience working with older adults. Three self-identified as supervisors of other social workers. All participants were White, all were female, and all but two worked full time. All of the professionals had attended some college; six had master's degrees and six had completed undergraduate programs. The educational backgrounds of participants included six studying social work, two in nursing, and two with a background in counseling/ family studies. Six participants worked at an Area Agency on Aging, two were in a hospital, two worked in adult protective services, and two were in a community crisis center. Other work settings were an agingfocused nonprofit and private practice with one participant at each.

\section{Data Collection}

This research was conducted following approval from the Ohio University Institutional Review Board. Between August, 2012 and May, 2013 the first author collected data through semi-structured interviews that were digitally recorded and transcribed. Some of the questions included, "What's it like to age in this community?" and "What are some of the values common to this area about care for older people?" Prior to each interview, participants signed a consent form; this included the purpose of the study, researcher contact information, audience for which the study is intended, and explanations of the voluntary nature of participation. All participants were assigned a pseudonym and names of towns mentioned by participants were changed. Participants were offered a $\$ 35$ gift card to a vendor of their choosing. Interviews averaged one hour in length.

\section{Data Analysis}

Grounded theory methods were used to analyze the data, specifically the techniques of coding and constant comparison. The first author read each of the 14 transcripts several times to get a sense of the data in its entirety. During initial reading of the transcripts, open coding procedures were employed, where codes were created from what was present in the data. After identifying initial codes in the transcripts, the first author moved to focused coding, which involved making decisions about what codes were most relevant to the research questions, discarding codes that were not relevant, and combining earlier codes that were similar. Constant comparison was used to look for similarities and differences in categories across the transcripts (Charmaz, 2014). To facilitate this, segments of data pertaining to participants' perceptions of rural aging (e.g. attitudes, beliefs, relevant experiences, statements) were copied and pasted into a separate document using Microsoft Word. Sorting the data into categories that emerged (i.e. informal support, limited health care resources, drug use) and assigning codes to segments of data occurred simultaneously and were iterative processes. 
Table 1. Participant Characteristics

\begin{tabular}{|c|c|c|c|c|c|c|c|}
\hline Participant & Age & Race & Educational Background & Program of Study & $\begin{array}{l}\text { Length of Time } \\
\text { Employed at Current Job }\end{array}$ & $\begin{array}{l}\text { Part-time/ Full } \\
\text { Time }\end{array}$ & Job Title \\
\hline Lydia & 46 & White & Bachelor's degree & Social Work & 21 years & $\begin{array}{l}\text { Full-time } \\
\text { Supervisor }\end{array}$ & $\begin{array}{l}\text { Hospital Social } \\
\text { Worker }\end{array}$ \\
\hline Tatum & 35 & White & Bachelor's degree & Social Work & 10 years & Full-Time & $\begin{array}{l}\text { Hospital Social } \\
\text { Worker }\end{array}$ \\
\hline Jacquelyn & 52 & White & Master's degrees & $\begin{array}{l}\text { Social Work, } \\
\text { Economics }\end{array}$ & 4 years & Part-Time & $\begin{array}{l}\text { Director of } \\
\text { Operations }\end{array}$ \\
\hline Amy & 36 & White & Master's degree & Family Studies & 14 years & $\begin{array}{l}\text { Full-time } \\
\text { Supervisor }\end{array}$ & Supervisor \\
\hline Courtney & 38 & White & Bachelor's degree & Nursing & 2 months & Part-Time & $\begin{array}{c}\text { Service } \\
\text { Coordinator }\end{array}$ \\
\hline Taylor & 24 & White & Bachelor's degree & Social Work & 2 years & Full-time & Case Manager \\
\hline Marge & 69 & White & Associate's degree & Nursing & $61 / 2$ years & Part-Time & Service Broker \\
\hline Joanne & 65 & White & Master's degree & Counseling & 25 years & Part-Time & $\begin{array}{l}\text { Therapist, grief } \\
\text { counselor }\end{array}$ \\
\hline Karen & 62 & White & Master's degree & Social Work & 24 years & Full-Time & Supervisor \\
\hline Terri & 48 & White & Bachelor's degree & Philosophy & $171 / 2$ years & Full-Time & $\begin{array}{l}\text { Case Manager/ } \\
\text { Assessor }\end{array}$ \\
\hline Linda & 51 & White & Some college & Marketing & 12 years & Full-Time & $\begin{array}{l}\text { Program } \\
\text { Coordinator }\end{array}$ \\
\hline Donna & 43 & White & Bachelor's degree & Social Work & 5 years & Full-Time & Case Manager \\
\hline Maggie & 38 & White & Master's degree & Counseling & $51 / 2$ years & Full-Time & Case Manager \\
\hline Carolyn & 62 & White & Master's degree & $\begin{array}{c}\text { Applied } \\
\text { Behavioral Science }\end{array}$ & 20 years & Full-Time & Supervisor \\
\hline
\end{tabular}


Member checks were used to help ensure rigor (Bogdan \& Biklen, 2007; Merriam, 2009). After preliminary interpretations of the data were developed, the first author sent a summary of the findings to seven participants via email. Three participants provided feedback on the common themes and adjustments were made based on their feedback, such as clarifying the label of a theme or category.

\section{Findings}

Three themes were identified concerning rural aging, as viewed from the perspective of social service providers in a rural region of North Central Appalachia: a scarcity of resources, a valuing of neighbors and family, and a high prevalence of drug abuse in the area. These themes are discussed below.

\section{Scarcity of Resources}

Aging in rural Appalachia is influenced by limited access to healthcare and social services, limited technology, poverty, and the distance one must travel to access care.

Maggie, who provided case management and mental health counseling at an Area Agency on Aging, discussed the trouble that many clients have in accessing healthcare services due to geographic isolation, poverty, and a shortage of medical care in the region:

The transportation to medical appointments is a big issue. It's gotten better recently in the rural area, but because a lot of the specialists are so far away, they have to drive. [Clients] have to somehow get themselves there. And they get max $\$ 700$ a month and they've got to figure out how they're going to get to the doctor and how they're going to buy their groceries. You know, the nearest grocery store for some people is twenty miles away.

Participants described their rural communities as having few medical doctors, resulting in clients having to commute to nearby large cities to receive specialized healthcare services.

A second example of scarce resources that was mentioned was insufficient social services for rural elders. Lydia, a hospital social worker, asserted that many older adults in her community are "geographically isolated" and many aging-related programs serve elders living in the city limits and not those living in more remote areas of the county: "[With] the senior programs we have-who are the folks that belong to them but the town folk?....as hard as we've tried over the years...to reach out to these outlying areas - those people don't come in to town."

Social isolation is often a consequence of scarce resources. A lack of transportation or access to social services can lead to limited interaction with other people. Linda, a program coordinator at an Area Agency on Aging, has observed this over her 12-year tenure in the agency. She stated that "loneliness [which] then leads to depression [which] leads to all sorts of ailments" was common for her clients.

Terri, a case manager with more than 17 years of experience at an Area Agency on Aging, discussed the limited technology where she lived and worked. 
Where I live, [there is] very little cell phone reception - actually no internet unless you want slow dial up through the phone or an expensive satellite. We don't have cable, we don't have broadband, you know, we don't have the pieces that a lot of these things are dictating now what you have to have access to. We still have a lot of technology deficits in this zone.

Accessing the internet was especially important for Terri's clients, who participated in a consumer-directed Medicaid waiver program where they, or their authorized representative, assumed responsibility for managing their own in-home services. These older clients act as the "employer of record" for their care providers and manage hiring, scheduling, and payroll duties for their service providers. An unreliable internet connection was a real hindrance for older adults or authorized representatives who need to access the web to input time sheets and enter data into an online system.

Lastly, intergenerational poverty was mentioned by several of the participants and is closely linked to the access issues facing many rural elders. For example, Donna, an Adult Protective Services case worker, observed: "You get out in rural areas where they don't live with running water, they don't have electricity...I've seen [clients who] use buckets to go to the bathroom. They've just lived this way their whole life."

Despite many participants describing a lack of resources in their rural area, two participants expressed different sentiments about this issue. Interestingly, both of these women worked at community crisis centers where the bulk of their job entailed connecting clients with community agencies and services; these two women also worked in the same town. When asked what it was like for older adults in her small town, Courtney, a service coordinator, said simply: "I think aging around here, I mean ...I think it's pretty good, actually." She described close immediate and extended families and local church and civic organizations that were concerned about their older community members. Similarly, Marge, a service broker, said, "I think resources are excellent around here. I think it's just that people just need to know the right questions to ask or the right person...but they're out there." The divergent perspectives of Courtney and Marge indicate between-site variation that emerged from interviewing aging services providers at different communities in southeast Ohio. Their comments also relate to the next theme to be discussed - the valuing of neighbors and families.

\section{Valuing of Neighbors and Family}

An aspect of aging in Appalachia that might counterbalance the poverty and scarcity in resources is the importance placed on neighbors and family. Taylor, the youngest participant in this study at age 24, spoke about informal support from fictive kin that is often present in rural communities:

I think that in small towns... a lot of people know people and have known their families for a long time. So [elders have] that informal support of maybe somebody who was-maybe it was somebody who was best friends with your mother-and so now they're going to a step up and take care of them. I think in small towns and in rural areas that happens a lot. I think that people are more aware of what's going on with everybody because everybody knows everybody. 
Jacquelyn, a social worker and director of an aging-focused nonprofit, shared similar observations from her own experiences.

In this region, we're going to take care of each other. I think it's really significant and I see that happen at all socioeconomic levels.... My mom and grandma are good examples of that. They've been adopted by I don't know how many people helping to take care of them. I think that goes on a lot.

In addition to neighbors providing informal support to older people, participants also observed strong attitudes toward filial responsibility and close family ties. Amy, a supervisor with Adult Protective Services, said simply, "families stick together in Appalachia as far as taking care of each other." She went on:

[They] may not be taking care of each other to the extent that I would think that it needed to be done, but you do see families saying "I'll take him", "I'll take him", "I'll take him." More so than just, "Well, just place them [in a nursing home]."

Courtney, a service coordinator and registered nurse, observed older adults in her area receiving much support from extended families: "There seems to be lots of, 'You know, my daughter comes in and does that for me' or 'Yeah, my niece does that for me."' Likewise, Tatum, a hospital social worker, shared, "a lot of times it's...like mom has two acres and everybody's got a trailer or a camper or something on the property and so they kind of stick together that way and they're very protective of each other."

Terri related what she has heard from adult children regarding parents' expectations for caregiving:

Several [clients] have indicated, "You know, Mom and/or Dad, they want me to take care of them forever, they want me to promise them that they'll never be put in a nursing home and I've made them that promise. But you know, I just can't do it anymore." I hear a lot of that. There's a lot of respect still in this area through our culture and the way that families are pretty tight still.

Carolyn, a supervisor with more than 20 years of experience working at an Area Agency on Aging, also spoke to this: "I think that a lot of family feel that they have to be responsible for the parent."

Despite cultural values that support expectations for family caregiving, several participants commented on the incongruity between filial responsibility and the reality of young people leaving the small towns. Karen, a supervisor at an Area Agency on Aging, shared:

I think the biggest thing that I've seen as far as the planning [for aging] is the tendency for the older generation to make assumptions based [on the idea] that you take care of the seniors in your family. That's their value and the younger generation doesn't have the ability to do that all the time because they've left the area because there are no jobs. [Young people] have had to go wherever to get them and they're not available to provide support and assistance that they would love to give [but] they just physically aren't there. So, it's not even a matter of a different value system-it's a matter of a different reality. 
Linda provided a similar outlook. In her town, increasing numbers of elders were being cared for by long-distance caregivers; she attributed this to the fact that many young adults had to relocate to larger towns and cities to access financial and educational opportunities. Linda observed, “There's no work here. Everybody's leaving to go find work and now everybody's running off to the big city to find jobs and pursue their dreams or what have you."

\section{Prevalence of Drug Abuse}

A third, somewhat surprising theme related to aging in a rural environment that emerged was the perception of rampant drug abuse problem in the region. Abuse of both illicit and prescription drugs is a public health concern in many rural communities that affects older adults and their family members. Maggie, who provided case management and counseling services through an Area Agency on Aging, shared about clients being addicted to both illicit and prescription drugs:

[Drug abuse] is starting to become pretty widespread in this area. We have lots of conversations about it. One of the workers actually had a consumer overdose on heroin.... We've had some arrested multiple times for drug usage and selling their [prescription] drugs. They are no longer in the program.

Participants also shared about older adults who profited from selling their prescription drugs. Linda described what she had heard from other case managers in her regional office: "I've heard of seniors selling their meds so they can buy groceries." Similarly, Karen had recently learned of older adults renting out their kitchen tables for people to use for selling drugs.

Drug use affects not only rural older adults who misuse, abuse, and sell them, but family members who have a significant role in these elders' lives. Carolyn, a supervisor, shared about the shift she had seen in her community and her work with older adults:

Some of the issues we're having are family members who are taking advantage of the parent. Some of them are the individual who has had a history of alcoholism or has become drug dependent. You know...lots of things are coming up that we've never had to deal with before. It's a whole new phase of case management!

Joanne, a social worker who specialized in caregiver support services and hospice, described what she had seen in her work: "Drugs are...a huge problem with family members or neighbors stealing them. People protect their family member and go without the needed drugs at times. They are not going to turn them in." Likewise, Donna, an Adult Protective Services case manager, mentioned family loyalty characteristic of Appalachians and how this affected elders and their interactions with relatives abusing drugs: "With the drug abuse in the Appalachian population - it's amazing. You have the elder population who doesn't want to say anything. They're never going to do anything against their grandkids. They're never gonna' do anything like that."

For participants in this study, drug abuse was not an issue typically thought to affect older adults. However, Appalachian elders are not immune from the drug abuse epidemic in the region, and health and social service providers have to adjust their approach to 
working with older clients and their families in light of this issue. Carolyn said, "There's a lot of drug and alcohol problems that never existed twenty years ago.... We're having to branch out and look at things differently... [and] look at issues and situations that we had never had to deal with before." Similarly, this comment from Karen gives additional insight into how drug abuse among the older population affects geriatric professionals:

[We have] service providers refusing to go in [to homes] and provide care because of the family members. It's seniors who are doing without the medications they need because family members borrow them. It's physicians being reluctant to prescribe the medications that individuals need because of certain assumptions.

Although not affecting the majority of clients, abuse and misuse of prescription and illicit drugs was an issue that these social service providers were facing.

\section{Discussion}

The purpose of this study was to learn more about rural aging, as viewed through the experiences of social service providers in a rural region of North Central Appalachia. Given that aging in Appalachia might look different than growing old in other regions of the United States, this study adds to the literature by having participants describe the experience of aging in rural Appalachia based on their work experience in geriatric social services. Themes surrounding growing old in this region were scarcity of resources, a valuing of neighbors and family, and a high prevalence of drug abuse.

It is not surprising that high rates of poverty and scarce health and social services were mentioned often by participants interviewed in this study. High rates of chronic illness and disability that are present among older rural elders are exacerbated by shortages in health and social services in these regions (Smith \& Holloman, 2011). Poor health outcomes are highly correlated with factors such as lower incomes and educational attainment which are more widespread in rural areas of the United States (Behringer \& Friedell, 2006). Additional burdens for rural older adults living with chronic conditions include less access to physicians, hospitals, and routine medical care. Although $25 \%$ of the U.S. population lives in rural areas, only $10 \%$ of physicians practice in these regions (Barley, Reeves, O'Brien-Gonzales, \& Westfall, 2001). Those living in rural communities are often geographically isolated, lack public transportation options, and have to travel long distances to access health and social services (Hartley, 2004; Krout, 1998). In the Rural Healthy People 2010 survey, access to quality health services (including primary care) was ranked as the top rural health priority with about $75 \%$ of respondents naming access as a priority (Gamm, Hutchison, Bellamy, \& Dabney, 2002).

In this study the importance of informal support from family and friends was a second prominent theme regarding aging in small communities. Historically, children of older adults would assume the responsibility of informal caregiving of their parents. This is often done in conjunction with raising their own children. An issue that complicates the ability for aging parents to receive care from their adult children is the rural population loss through outmigration of young people. One effect this may have on elders is that it limits the availability of unpaid family caregivers to provide assistance when chronic illness or disability necessitates the need for care (Carter \& Wang, 2006). This was reflected in 
participant comments about the conflict between attitudes towards filial responsibility for aging relatives and the reality of potential family caregivers relocating to larger cities. However, participants described support provided to elders not only by family, but also by fictive kin. This supports other evidence of a social structure in Appalachia based on fictive kin (e.g., close neighbors, fellow church members) as well as blood relatives, possibly because in isolated communities these are the individuals with whom one usually interacts (Russ, 2010). These extended family networks may be a resource for older adults in the region whose blood relatives are no longer living nearby. Another effect of outmigration is the loss of the "professional and leadership skills" that "young and educated people leaving for more prosperous areas and opportunities" take with them (HAC, 2012, p. 67). Thus, within rural Central and North Central Appalachia there may be a loss of both familial informal and skilled formal caregivers for the aging population.

Finally, an unanticipated theme that emerged about aging in rural Appalachia was how prevalent drug abuse in the region influenced older adults and their well-being. Like stories from participants in this study, Basta, Della, and Ashlock (2013) found that the selling of prescription drugs in Appalachia is closely linked to the depressed economy; individuals often resort to selling their prescriptions to pay for basic needs like food and utility costs. Older adults, they found, were also not excluded from drug abuse. One participant in their recent study commented: “...the sad part of it is people my age, which is in the 60's, there has been drug overdoses from that age because they got hurt in the coal mines, they got hooked on drugs" (Basta et al., slide 13). Certainly a factor in substance abuse among rural elders is the fact that older people use prescription drugs about three times more often than the general population. Representing only $13 \%$ of the U.S. population, individuals 65 and older consume 25 to $33 \%$ of all prescription drugs (Richardson \& Barusch, 2006) and 25\% of elders are taking psychoactive medications with abuse potential (Simoni-Wastila \& Yang, 2006). Research has also identified a strong relationship between therapeutic exposure to opioid analgesics and abuse of these drugs (Cicero, Surratt, Inciardi, \& Muñoz, 2007).

Data suggests that rates of prescription drug abuse in Appalachia are congruent with the rest of the country-5.6\% and 5.9\% respectively (ARC, 2008). However, high unemployment rates may influence prescription drug use in rural North Central Appalachia (Thornton \& Deitz-Allen, 2010). The ease with which drugs are made available by physicians (Leukefeld, Walker, Havens, Leedham, \& Tolbert, 2007; Schoenberg, Hatcher, \& Dignan, 2008), influence from peers and families (Leukefeld et al., 2007), and cultural acceptance of drug misuse (Leukefeld et al., 2007) may also contribute to prescription drug abuse in the region. In addition, the region has witnessed a recent crackdown on the prescription drug abuse trade by state and local officials. For example, in Scioto County, Ohio (within the geographic boundary of the current study), heroin use is on the rise and has been since the community came together to eliminate "pill mills" and ameliorate the prescription drug epidemic (Roberts, 2012).

\section{Limitations}

A central aim of qualitative research inquiry is to provide in-depth descriptions of a phenomenon, using a small sample of information-rich cases. Therefore, the findings of 
this study should be cautiously applied to other groups. These participant descriptions of rural aging will not necessarily hold true for all rural and/ or Appalachian regions of the US. In addition, study participants were limited to direct service providers for older adults. Potential participants might have not responded to the recruitment flier because they did not identify with the selection criteria or the language used in eligibility requirements. Despite these limitations, this study highlights the voices of 14 seasoned geriatric social service providers, because the focus was to understand rural aging from their perspectives.

\section{Implications for Social Work Research, Education, and Practice}

This study adds to the developing knowledge about aging and aging services in rural areas of the U.S. Given the small regional focus and sample size, this research can serve as a jumping off point for future work aimed at understanding the realities of growing old in the $21^{\text {st }}$ century. Based upon results of this study, it seems that future research in this area must address the following: 1) the complexities of familial relationships and aging, including the role that fictive kin may play in the lives of older adults, 2) access to services and service discrepancies between rural and urban communities, 3) how older adults engage in/utilize technology and what barriers exist related to the burgeoning tech-driven models (e.g., tele-medicine, web-based services) in rural communities, and 4) substance abuse - particularly prescription drug abuse - and aging.

This study revealed that older adults are very much impacted by substance abuse and misuse. While social work students often study substance use and misuse, they may not be prepared for the realities of how substance abuse affects older people and their family caregivers. Resources for instructors interested in infusing gerontology content into substance abuse courses are available online at the Council on Social Work Education Gero-Ed Center (http://www.cswe.org/TeachingInfusion.aspx). By challenging common beliefs about substance abuse in the classroom, students can be better prepared to engage with the complexities in their caseloads. Findings from this study also highlight the need for awareness and attention to be brought to the drug issue in Appalachia - particularly its effects on the older rural population. Future research needs to explore the ways in which older adults engage in illicit activity with prescription drugs, the vulnerability of older adults in prescription drug fraud/sales, and the protections available to older adults who may be victimized, such as those who have their prescriptions sold or stolen. The grassroots efforts of those in Scioto County, Ohio (Roberts, 2012) serve as an example for communities looking to fight the prescription drug epidemic. Campaigns to oppose "pill mills" should certainly consider the needs of older citizens, as well as the susceptibility of this group to prescription drug abuse. Moreover, social workers should be at the center of these efforts.

The knowledge gained from this study can also help social work educators prepare students to be effective in working with older adults in rural agencies and communities. For example, participants in this study identified family and fictive kin as important resources for elders in their small towns. Students need to be made aware of the complexities of family dynamics and the role that family (fictive and relational) plays in the aging process. While many rural regions in the U.S. have been characterized by their strong social support networks, it is crucial to have culturally competent and sensitive 
social workers in such regions who can build upon the strengths of such social support networks. In order to get a strong cohort of skilled social workers in the rural areas who are also interested in older adults (especially at the masters level), it would advantageous to extend the benefits of loan repayment programs to geriatric social workers practicing in rural regions, like the loan repayment options available to physicians who commit to working in a rural area.

\section{References}

AARP. (2000). Fixing to stay: A national survey on housing and home modification issues. Washington, DC: Author.

Alley, D., Liebig, P., Pynoos, J., Banerjee, T., \& Choi, I. H. (2007). Creating elderfriendly communities: Preparations for an aging society. Journal of Gerontological Social Work, 49(1/2), 1-18. doi:10.1300/J083v49n01

Appalachian Regional Commission [ARC]. (2008). An analysis of mental health and substance abuse disparities and access to treatment services in the Appalachian Region. Retrieved from http://www.arc.gov/research/researchreportdetails.asp?REPORT ID=71

ARC. (2009). Source and methodology. Retrieved from http://www.arc.gov/research/SourceandMethodologyGeography.asp

Baldwin, L.-M., Cai, Y., Larson, E. H., Dobie, S. A., Wright, G. E., Goodman, D. C., . . . Hart, L. G. (2008). Access to cancer services for rural colorectal cancer patients. The Journal of Rural Health, 24(4), 390-399. doi:10.1111/j.1748-0361.2008.00186

Barker, L., Gerzoff, R., Crespo, R., \& Shrewsberry, M. (2011). Age at diagnosis of diabetes in Appalachia. Population Health Metrics, 9(54), 1-8. doi:10.1186/14787954-9-54

Barley, G. E., Reeves, C. B., O-Brien-Gonzales, A., \& Westfall, J. M. (2001). Characteristics of and issues faced by rural female family physicians. Journal of Rural Health, 17(3), 251-258. doi:10.1111/j.1748-0361

Basta, T., Della, L., \& Ashlock, M. Z. (2013). Perceptions of drug abuse among residents in rural eastern Appalachian Kentucky [PowerPoint Slides]. Presented at the Appalachian Health Summit, Columbus, Ohio.

Behringer, B., \& Friedell, G. H. (2006). Appalachia: Where place matters in health. Preventing Chronic Disease, 3(4), A113. Retrieved from http://www.ncbi.nlm.nih.gov/pmc/articles/PMC1779277/

Blieszner, R., Roberto, K. A., \& Singh, K. (2002). The helping networks of rural elders: Demographic and social psychological influences on service use. Ageing International, 27(1), 89-119. doi:10.1007/s12126-001-1017-2

Bogdan, R. C., \& Biklen, S. K. (2007). Qualitative research in education: An introduction to theory and methods ( $4^{\text {th }}$ ed.). Boston, MA: Allyn and Bacon. 
Buckwalter, K. C., \& Davis, L. L. (2011). Rural caregiving in the United States. In R. C. Talley, K. Chwalisz, \& K. C. Buckwalter (Eds.), Caregiving: Research, practice, policy (pp. 33-46). New York, NY: Springer.

Carter, M. W., \& Wang, S. (2006). Quality of care in Appalachian nursing homes: Doing more with less. Retrieved from http://www.rri.wvu.edu/pdffiles/carterwp2006-6.pdf

Charmaz, K. (2014). Constructing grounded theory: A practical guide through qualitative analysis ( $2^{\text {nd }}$ ed.). London: Sage.

Cicero, T. J., Surratt, H. L., Inciardi, J. A., \& Muñoz, A. (2007). Relationship between therapeutic use and abuse of opioid analgesics in rural, suburban, and urban locations in the United States. Pharmacoepidemiology and Drug Safety, 16(8), 827-840. doi: $10.1002 /$ pds. 1452

Coyne, C. A., Demian-Popescu, C., \& Friend, D. (2006). Social and cultural factors influencing health in southern West Virginia: A qualitative study. Preventing Chronic Disease, 3(4), A124.

Della, L. J. (2011). Exploring diabetes beliefs in at-risk Appalachia. The Journal of Rural Health, 27(1), 3-12. doi:10.1111/j.1748-0361.2010.00311.x

Deskins, S., Harris, C. V., Bradlyn, A. S., Cottrell, L., Coffman, J. W., Olexa, J., \& Neal, W. (2006). Preventive care in Appalachia: Use of the theory of planned behavior to identify barriers to participation in cholesterol screenings among West Virginians. The Journal of Rural Health, 22(4), 367-374. doi:10.1111/j.1748-0361.2006.00060.x

Furnham, A. (1994). Explaining health and illness: Lay perspectives on current and future health, the causes of illness, and nature of recovery. Social Science and Medicine, 39(5), 715-725. doi:10.1348/135910708X370781

Gamm, L., Hutchison, L., Bellamy, G., \& Dabney, B. J. (2002). Identifying rural health priorities and models for practice. Journal of Rural Health, 18(1), 9-14. doi:10.1111/j.1748-0361.2002.tb00869.x

Haaga, J. (2004, April). Demographic and socioeconomic change in Appalachia: The aging of Appalachia. Retrieved from http://www.prb.org/pdf04/AgingofAppalachia.pdf

Halverson, J., Barnett, E., \& Casper, M. (2002). Geographic disparities in heart disease and stroke mortality among black and white populations in the Appalachian region. Ethnicity \& Disease, 12(4), 82-91.

Halverson, J., Ma, L., \& Harner, E. J. (2004). An analysis of disparities in health status and access to health care in the Appalachian region. Washington, DC: Appalachian Regional Commission. Retrieved from http://www.arc.gov/research/researchreportdetails.asp?REPORT ID=82

Hartley, D. (2004). Rural health disparities, population health, and rural culture. American Journal of Public Health, 94(10), 1675-1678. doi:10.2105/AJPH.94.10.1675 
Hayes, P. A. (2006). Home is where their health is: Rethinking perspectives of informal and formal care by older rural Appalachian women who live alone. Qualitative Health Research, 16(2), 282-297. doi:10.1177/1049732305275629

Houser, A. N., Fox-Grage, W., \& Gibson, M. J. (2009, March). Across the states 2009: Profiles of long-term care and independent living. Washington, DC: AARP Public Policy Institute. Retrieved from http://assets.aarp.org/rgcenter/il/d19105 2008 ats.pdf

Housing Assistance Council [HAC]. (2012). Taking stock: Rural people, poverty, and housing in the $21^{\text {st }}$ Century. Washington, DC: Author. Retrieved from http://ruralhome.org/storage/documents/ts2010/ts_full_report.pdf

Kinsella, K., \& Velkoff, V. (2001). An aging world: 2001. U.S. Census Bureau Series P95/ 01-1. Washington, DC: U.S. Government Printing Office.

Kropf, N. P. (2004). Future training and education recommendations for rural gerontological social workers. Journal of Gerontological Social Work, 41, 287-299. doi:10.1300/J083v41n03_06

Krout, J. A. (1998). Aging in rural environments. In R. T. Coward \& J. A. Krout (Eds.), Aging in rural settings: Life circumstances and distinctive features (pp. 247-265). New York, NY: Springer.

Lengerich, E. J., Bohland, J. R., Brown, P. K., Dignan, M. B., Paskett, E. D., Schoenberg, N. E., \& Wyatt, S. W. (2006). Images of Appalachia. Preventing Chronic Disease: Public Health Research, Practice, and Policy, 3(4), A112.

Lengerich, E. J., Tucker, T. C., Powell, R. K., Colsher, P., Lehman, E., Ward, A. J., . . . Wyatt, S. W. (2005). Cancer incidence in Kentucky, Pennsylvania, and West Virginia: Disparities in Appalachia. The Journal of Rural Health, 21(1), 39-47. doi:10.1111/j.1748-0361.2005.tb00060.x

Leukefeld, C., Walker, R., Havens, J., Leedham, C. A., \& Tolbert, V. (2007). What does the community say: Key informant perceptions of rural prescription drug use. Journal of Drug Issues, 37(3), 503-524. doi:0022-0426/07/02

Merriam, S. B. (2009). Qualitative research: A guide to design and implementation. San Francisco, CA: Jossey-Bass.

Ohio Environmental Protection Agency. (n.d.). Southeast district map. Retrieved from http://epa.ohio.gov/Default.asps?alia+epa.ohio.gov/sedo

Patton, M. Q. (2002). Qualitative research and evaluation methods ( $3^{\text {rd }}$ ed.). Thousand Oaks, CA: Sage.

Pollard, K., \& Jacobson, L. (2014). The Appalachian Region: A data overview from the 2008-2012 American Community Survey. Retrieved from http:/www.arc.gov/assets/research_reports/DataOverviewfrom2008-2012ACS.pdf

Pope, N. D. (2013). Female caregivers' plans for later life. Qualitative Social Work, 12(4), 507-522. doi:10.1177/1473325012442439 
Richardson, V. E., \& Barusch, A. S. (2006). Gerontological practice for the Twenty-First Century: A social work perspective. New York, NY: Columbia University Press.

Roberts, L. (2012, October). Waging the war against the devil in Scioto County: A grassroots response to prescription drug abuse in a rural community. Presentation at the Addiction Health Services Research conference, Fairfax, VA. Retrieved from http://ctndisseminationlibrary.org/display/765.htm

Russ, K. A. (2010). Working with clients of Appalachian culture. Retrieved from http://counselingoutfitters.com/vistas/vistas10/Article_69.pdf

Schoenberg, N. E., Hatcher, J., \& Dignan, M. B. (2008). Appalachian women's perceptions of their community's health threats. Journal of Rural Health, 24(1), 7583. doi:10.1111/j.1748-0361.2008.00140.x

Simoni-Wastila, L., \& Yang, H. K. (2006). Psychoactive drug abuse in older adults. American Journal of Geriatric Pharmacotherapy, 4(4), 380-394. doi:10.1016/j.amjopharm.2006.10.002

Slovak, K., Sparks, A., \& Hall, S. (2011). Attention to rural populations in social work's scholarly journals. Journal of Social Service Research, 37(4), 428-438. doi:10.1080/01488376.2011.578035

Smith, L. H., \& Holloman, C. (2011). Health status and access to health care services: A comparison between Ohio's rural non-Appalachian and Appalachian families. Family \& Community Health, 34(2), 102-110. doi:10.1097/FCH.0b013e31820de961

Thornton, G. B., \& Deitz-Allen, K. (2010). Substance abuse, unemployment problems, and the disparities in mental health services in the Appalachian southwest region. Journal of Human Behavior in the Social Environment, 20(7), 939-951. doi:10.1080/10911359.2010.516690

\section{Author note}

Address correspondence to: Natalie Pope, Ph.D., University of Kentucky, College of Social Work, 610 Patterson Office Tower, Lexington, KY 40506. Email: ndpo224@uky.edu 